\title{
Topical nitric oxide relieved pain and symptoms in chronic extensor tendinosis at the elbow
}

Paoloni JA, Appleyard RC, Nelson J, et al. Topical nitric oxide application in the treatment of chronic extensor tendinosis at the elbow: a randomized, double-blinded, placebo-controlled clinical trial. Am J Sports Med 2003;31:915-20.

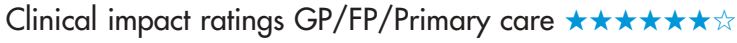

\section{In patients with chronic extensor tendinosis at the elbow (tennis elbow), does topical nitric oxide improve outcome?}

\section{METHODS}

-

Design: randomised controlled trial.

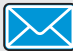

Allocation: $\left\{\right.$ concealed $\left.^{*}\right\}$ t

Blinding: blinded (patients and outcome assessors).*

Follow up period: 6 months.

Setting: Sydney, New South Wales, Australia.

Patients: 86 patients (95 elbows) who were $30-74$ years of age (median age $46 \mathrm{y}, 51 \%$ women) and had extensor tendinosis for $\geqslant 3$ months. Exclusion criteria: pregnancy, previous surgery, dislocation of the affected wrist or elbow, distal neurological signs, or a local corticosteroid injection in the previous 3 months.

R Intervention: 43 patients were allocated to an active transdermal patch $11 / 4$ of a $5 \mathrm{mg}$ per 24 hour Nitro-dur patch, SchleringPlough, Sydney, Australia). 43 patients received a matching placebo transdermal patch. Patients also received 24 paracetamol tablets (500 mg/tablet) to use as needed and were instructed in a tendon rehabilitation programme.

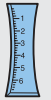

Outcomes: Patient rated elbow pain (0-4 [severe]) at rest, with activity, or at night; local epicondylar and tendon tenderness $(0$ to 3 [severe]); and wrist extensor mean peak force and mean total work.

무 Patient follow up: $86 \%$ (analysis was by intention to treat).

* See glossary.

tInformation provided by author.

\section{MAIN RESULTS}

The nitric oxide group had a greater decrease in elbow pain with activity at week $2(p=0.01)$, a greater decrease in lateral epicondylar and tendon tenderness at weeks $6(\mathrm{p}=0.02)$ and $12(\mathrm{p}=0.02)$, and a greater increase in mean peak force at week $24(\mathrm{p}=0.03)$ and mean total work at week $24(\mathrm{p}=0.03)$ than did patients in the placebo group. More patients in the nitric oxide group than the placebo group were asymptomatic during activities of daily living at week 24 (table).

\section{CONCLUSION}

In patients with chronic extensor tendinosis at the elbow, topical nitric oxide led to clinical improvement.

\section{Commentary}

M any treatments have been used for lateral epicondylitis, but little evidence supports their long term effectiveness. Although it has been shown that steroid injections provide early pain relief for $\leqslant 6$ weeks after treatment, no long term benefit has been shown, and detrimental effects may exist. ' A simple wait and see approach may still be the best long term strategy. ${ }^{2}$

The study by Paoloni et al is a well designed double blind study that shows improvement in pain and tenderness in all patients (including the placebo group) over the 24 week study period. However, patients treated with nitric oxide showed greater improvement than the placebo group. Those receiving the intervention also experienced more side effects-most notably headaches. $65 \%$ of patients in the nitric oxide group reported side effects, which were severe enough in $12 \%$ (overall) to discontinue treatment.

Activity modification to minimise repetitive stress is recognised as the first step in the treatment of tennis elbow. A simple wait and see approach, ${ }^{2}$ perhaps combined with physiotherapy and oral or topical NSAIDs, ${ }^{3}$ should suffice for most acute cases. Nitric oxide treatment may have a role in the treatment of chronic tennis elbow. When considering its use, patients should be screened for contraindications to nitroglycerin and warned about side effects.

Hans J Kreder, MD, MPH, FRCS(C) University of Toronto,

Sunnybrook \& Women's College Health Sciences Centre Toronto, Ontario, Canada

1 Smidt N, Assendelft WJ, van der Windt DA, et al. Corticosteroid injections for lateral epicondylitis: a systematic review. Pain 2002;96:23-40.

2 Smidt N, van der Windt DA, Assendelft WJ, et al. Corticosteroid injections, physiotherapy, or a wait-and-see policy for lateral epicondylitis: a

randomised controlled trial. Lancet 2002;359:657-62.

3 Green S, Buchbinder R, Barnsley L, et al. Non-steroidal anti-inflammatory drugs (NSAIDs) for treating lateral elbow pain in adults. Cochrane Database Syst Rev 2004(1):CD003686.

Topical nitric oxide $v$ placebo for chronic extensor tendinosis at the elbow*

\begin{tabular}{lllll}
\hline Outcomes at 24 weeks & Nitric oxide & Placebo & RBI (95\% Cl) & NNT (Cl) \\
\hline Asymptomatic during ADLs & $81 \%$ & $60 \%$ & $35 \%(2.6$ to 83$)$ & 5 (3 to 61) \\
\hline${ }^{*} \mathrm{ADLs}=$ activities of daily living. Other abbreviations defined in glossary; RBI, NNT, and Cl calculated from data in article.
\end{tabular}

For correspondence: Professory G A C Murrell, University of New South

Wales, Sydney, New South Wales, Australia. murrell.g@ori.org.au

Source of funding: in part, St George Hospital-South Eastern Sydney Area

Health Services. 